\title{
Comparison of Currently Used Prediction Models for Creep and Shrinkage of Concrete
}

\author{
Alena Zemanová*, Petr Tej, Petr Pokorný and Jiř́i Kolísko \\ Klokner Institute, Czech Technical University in Prague, Czech Republic \\ ${ }^{*}$ Corresponding author
}

\begin{abstract}
This paper presents a comparison of several currently used prediction models for creep and shrinkage of concrete. Compared models were: EN 1992-1-1 (2004), RILEM Model B3 (1995), MC 2010, GL Model 2000, ACI 209R (1992), AS 3600 (1988) and BS 8110 (1985). The comparison was made on slabs with two different thicknesses, two concretes with different strength and with the introduction of load in 7 and 28 days.
\end{abstract}

\section{Keywords-concrete; creep; shrinkage;prediction model}

\section{INTRODUCTION}

Time-dependent deformation of concrete may be dependent or independent of stress. Stress-dependent strain is called creep. These strains are defined as the difference between the increases in strain at the time of a specimen exposed to constant stress and strain sustained independent of load measured on the unloaded specimen. The creep depends on the material properties of the concrete components and the properties of the surrounding environment. It may be considered proportional to the volumetric share of the cement paste. Increases with increasing capillary porosity, with an increasing water ratio. Decreases with increasing age of the concrete at the time of introduction of load. Thin concrete elements takes shape more quickly because they are subject to rapid loss of moisture. [1] The same physical processes influence associated phenomenon called stress relaxation. Relaxation stress is the stress drop with time at constant deformation.

Deformation not depending on stress is called the shrinkage (or swelling that occurs at a relative humidity greater than 95\%). Shrinkage can be divided into two components, on autogenous and shrinkage of drying out. Autogenous shrinkage is related to chemical changes in hardening concrete. It arises due to the volume reduction during the hydration of cement, i.e. volume of the hardened cement paste is less than the volume of cement and water prior to the start of a chemical reaction. Shrinkage of drying is affected by loss of water in the concrete. The primary cause of the changes in capillary tension of pore system of hydrated cement paste and the change in surface energy due to the hydration products of changes in moisture content. Shrinkage is defined as the time-dependent change in volume of the concrete members, not subject to any external stress at constant temperature. Factors affecting shrinkage are concrete composition, density (strength) of concrete, ambient humidity, dimensions and cross-sectional shape and period of concrete curing of concrete [1].
Deformation of concrete can be divided according to several aspects listed in the table:

\begin{tabular}{|l|l|l|l|l|}
\hline $\begin{array}{l}\text { Deformation } \\
\text { of concrete }\end{array}$ & $\begin{array}{l}\text { reversible }- \\
\text { independent } \\
\text { of stress }\end{array}$ & $\begin{array}{l}\text { irreversible } \\
\text { independent } \\
\text { of stress }\end{array}$ & $\begin{array}{l}\text { reversible } \\
\text { induced } \\
\text { ind }\end{array}$ & $\begin{array}{l}\text { irreversible } \\
\text { stress } \\
\text { induced }\end{array}$ \\
\hline Short term & $\begin{array}{l}\varepsilon_{\mathrm{t}}- \\
\text { temperature } \\
\text { related }\end{array}$ & - & $\begin{array}{l}\varepsilon_{\mathrm{el}}- \\
\text { flexible }- \\
\text { Hook's } \\
\text { law }\end{array}$ & $\begin{array}{l}\varepsilon_{\mathrm{pl}} \\
\text { plasticity }\end{array}$ \\
\hline Long term & - & $\begin{array}{l}\varepsilon_{\mathrm{s}} \\
\text { shrinkage }\end{array}$ & $\begin{array}{l}\varepsilon_{\mathrm{c}} \\
\text { flexible } \\
\text { creep }\end{array}$ & $\begin{array}{l}\varepsilon_{\mathrm{c}} \\
\text { irreversible } \\
\text { creep }\end{array}$ \\
\hline
\end{tabular}

The total transformation that occurs at time $t$ in concrete elements exposed to continuous, uniaxial strain can be expressed as [2]:

$$
\varepsilon_{\mathrm{c}}(\mathrm{t})=\varepsilon_{\mathrm{c \sigma}}(\mathrm{t})+\varepsilon_{\mathrm{c}}(\mathrm{t})
$$

where: $\varepsilon_{\mathrm{c} \sigma}(\mathrm{t})=\varepsilon_{\mathrm{ci}}\left(\mathrm{t}_{0}\right)+\varepsilon_{\mathrm{cc}}(\mathrm{t})$ the total strain dependent on stress in the age of concrete $t$,

$\varepsilon_{\mathrm{cn}}(\mathrm{t})=\varepsilon_{\mathrm{cs}}(\mathrm{t})+\varepsilon_{\mathrm{cT}}(\mathrm{t}, \mathrm{T})$ the total strain independent on stress in the age of concrete $t$.

After substituting in the first equation can be written:

$$
\varepsilon c(t)=\varepsilon c i(t 0)+\varepsilon c c(t)+\varepsilon c s(t)+\varepsilon c T(t, T)
$$

where: $\varepsilon_{\mathrm{ci}}\left(\mathrm{t}_{0}\right)$ initial strain dependent on stress at the time of introduction of the load, the elastic deformation,

$\varepsilon_{\text {cc }}(\mathrm{t})$ creep strain at the age of concrete $\mathrm{t} \geq \mathrm{t}_{0}$,

$\varepsilon_{\mathrm{cs}}(\mathrm{t})$ shrinkage or swelling in the age of concrete $\mathrm{t}$,

$\varepsilon_{\mathrm{cT}}(\mathrm{t}, \mathrm{T})$ strain caused by temperature changes in the age of concrete $t$.

Expressing deformation via creep coefficient:

$$
\varepsilon(\mathrm{t}, \mathrm{t} 0)=\sigma(1+\varphi(\mathrm{t}, \mathrm{t} 0)) / \mathrm{E}(\mathrm{t} 28)
$$

where: $\varphi\left(t, t_{0}\right)$ is creep coefficient,

$\sigma$ is stress of constant intensity,

$t_{0}$ is the initiation of stress,

$\varphi\left(t, t_{0}\right)$ is a number with that is necessary to multiply the short-term deformation to get a long-term deformation caused by creep. It takes values between 0-6. Based on experiments various models are formulated. 


\section{COMPARISON OF SEVERAL Methods USED FOR PREDICTION OF CREEP AND SHRINKAGE}

Compared models are: EN 1992-1-1 (2004), RILEM Model B3 (1995), MC 2010, GL Model 2000, ACI 209R (1992), AS 3600 (1988), BS 8110 (1985).

Compared are the regulations used to predict creep and shrinkage in the standard EN 1992-1-1 [2], B3 model [3] and other models worldwide commonly used. B3 model was developed based on extensive experiments by the authors Z.P. Bažant and S. Baweja at Northwestern University in the US. It is the third modification of previous models - BP Model 1978 and Model KX-BP from 1991. BP-KX model had extended and shortened form. Extended form was intended for the construction of highly sensitive to the effects of creep. B3 model was designed to meet the requirements RILEM TC 107. It includes material properties, the influence of the environment and the size of the element. Thanks to its structure, it allows easy updating of its parameters based on the results of short-term measurements performed on the concrete used in construction or the concrete which usage is intended in the structure. Compliance function $\mathrm{J}$ is divided into three components. Member of "q1" is an immediate strain,

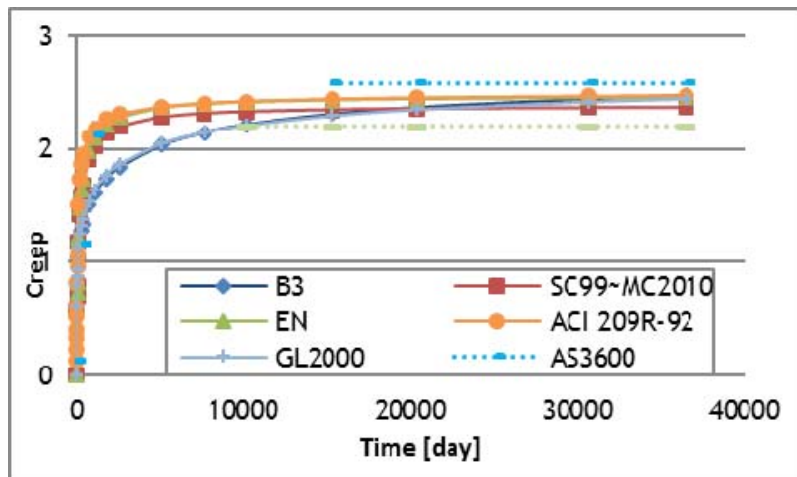

a) members of the "q2", "q3" and "q4" basic creep - strain at a constant humidity and temperature and a member of the "q5" drying creep - the effect of shrinkage from drying section. [3] This model is very complex, with choices largest number of input parameters. His mathematical structure was compiled by a vast number of experiments [3].

Prediction model MC 2010 [4] is listed in the bulletin, The International Federation for Structural Concrete (fib Fédération internationale du béton). Model Code 2010 builds on the earlier procedures published in the CEB - FIP 1970, the CEB - FIP 1978, the CEB - FIP 1990 SC 99 (Structural Concrete). GL Model 2000 [5] was developed by N.J. Gardner and M.J. Lockman. It builds on earlier GZ Model 1993, whose authors are Gardner and J.W. Zhao. For interest are implemented into the comparison ACI 209R model from 1992 (American Concrete Institute), Australian Standard AS 3600 Model Code of 1988 [6] and the model of British Standard BS 8110 from 1985 [5]. Using of models is intended for normal strength concrete (NSC) and for relative humidity of $40-80 \%$ [7]. The comparison is made for slabs of the thickness of 0.35 $\mathrm{m}$ and $1 \mathrm{~m}$ of concrete class of $\mathrm{C} 30 / 37$ and $\mathrm{C} 50 / 60$ and for the introduction of load 7 and 28 days.

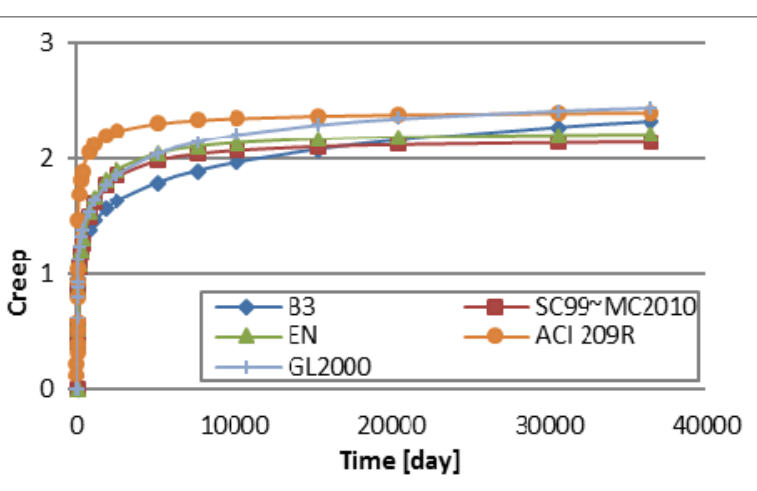

b)

FIGURE I. COMPARED CREEP COEFFICIENT, C30/37 CONCRETE, LOAD INTRODUCTION 7 DAYS, THICKNESS A) 0,35 M, B) $1 \mathrm{M}$

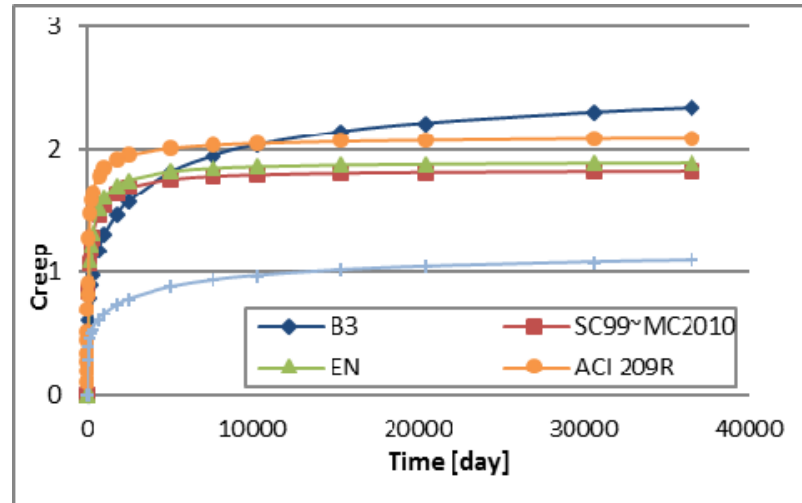

a)

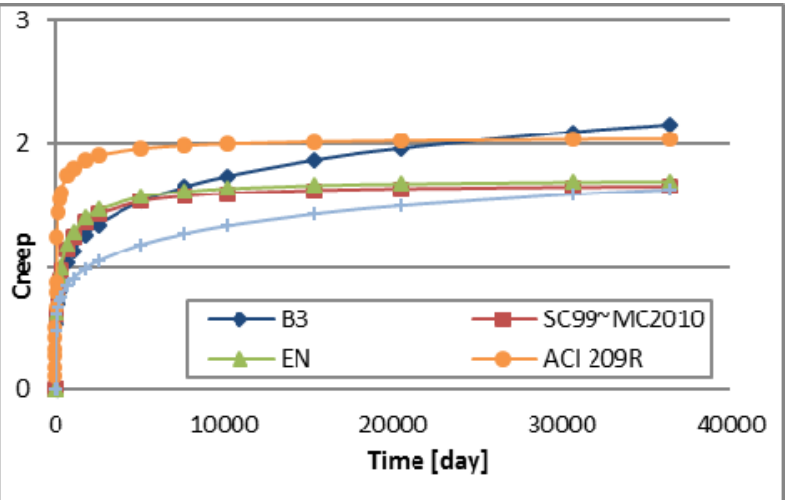

b)

FIGURE II. COMPARED CREEP COEFFICIENT, C30/37 CONCRETE, LOAD INTRODUCTION 28 DAYS, THICKNESS A) 0,35 M, B) 1 M 


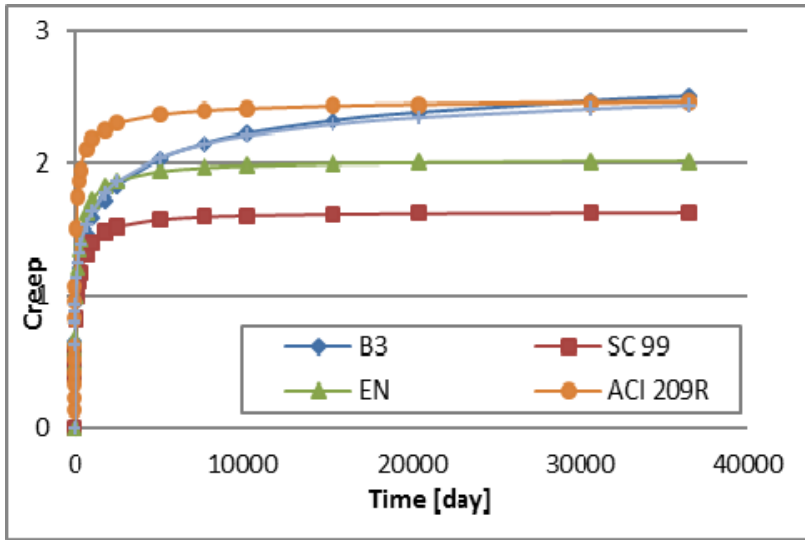

a)

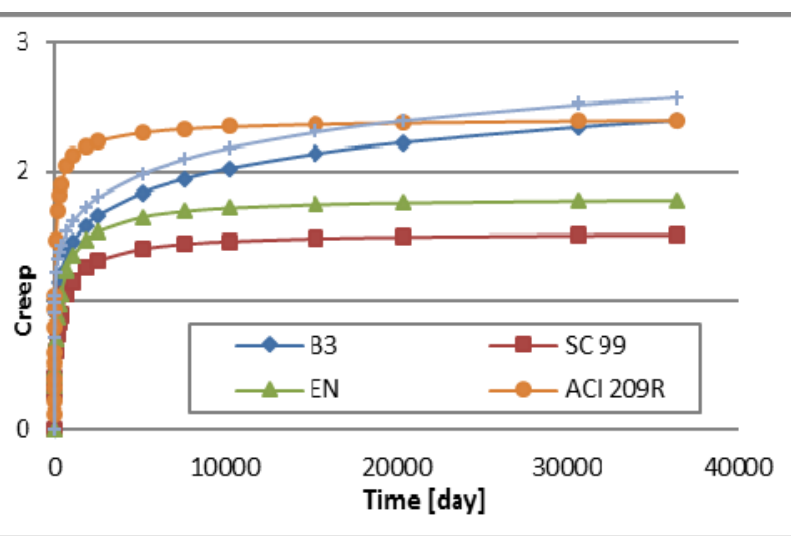

b)

FIGURE III. COMPARED CREEP COEFFICIENT, C50/60 CONCRETE, LOAD INTRODUCTION 7 DAYS, THICKNESS A) 0,35 M, B) 1 M

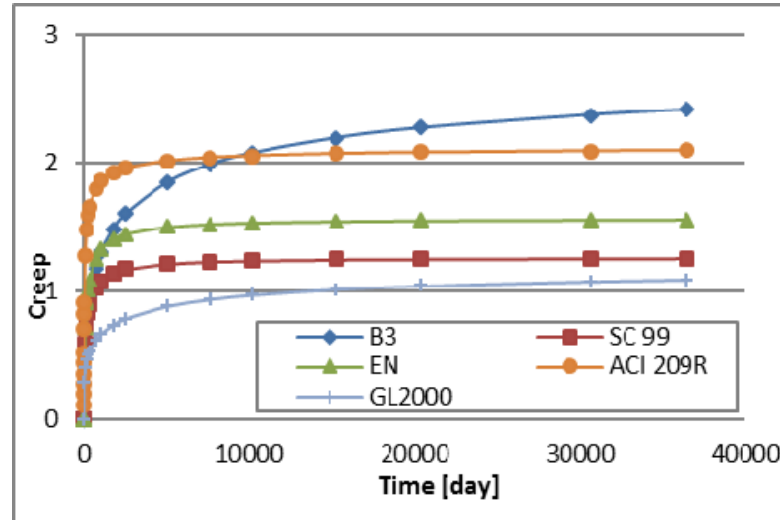

a)

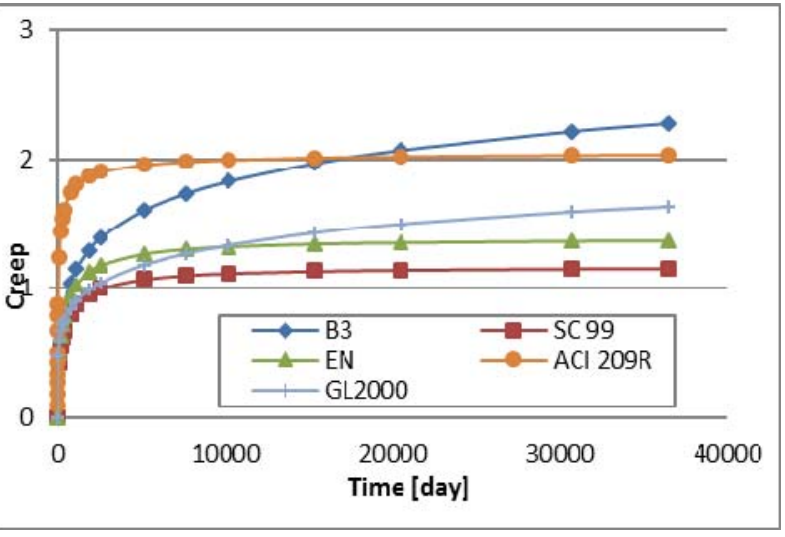

b)

FIGURE IV. COMPARED CREEP COEFFICIENT, C50/60 CONCRETE, LOAD INTRODUCTION 28 DAYS, THICKNESS A) 0,35 M, B) 1 M

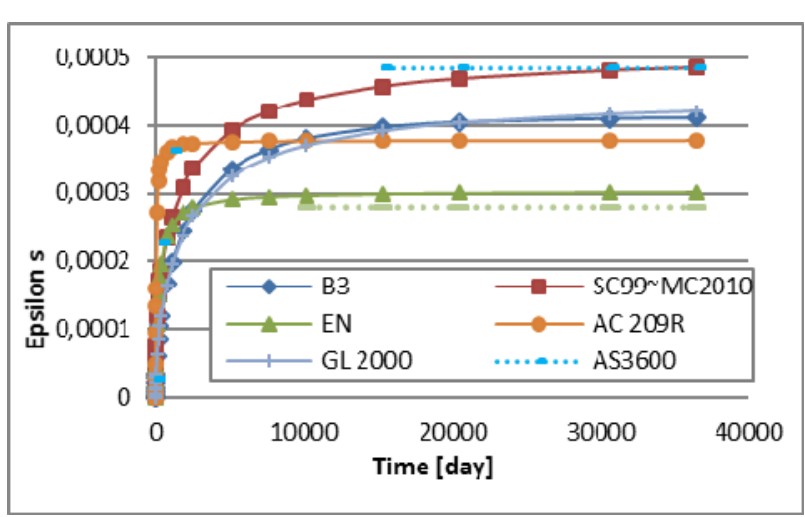

a)

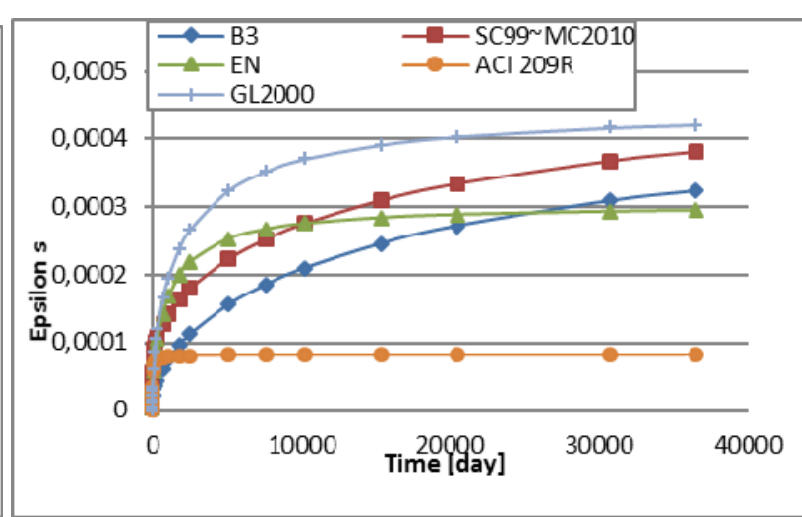

b)

FIGURE V. COMPARED SHRINKAGE, C30/37 CONCRETE, 0.35 M, NORMALLY HARDENING CEMENT, TREATMENT TIME 2 DAYS, RELATIVE HUMIDITY 70\%), THICKNESS A) $0,35 \mathrm{M}, \mathrm{B}) 1 \mathrm{M}$ 


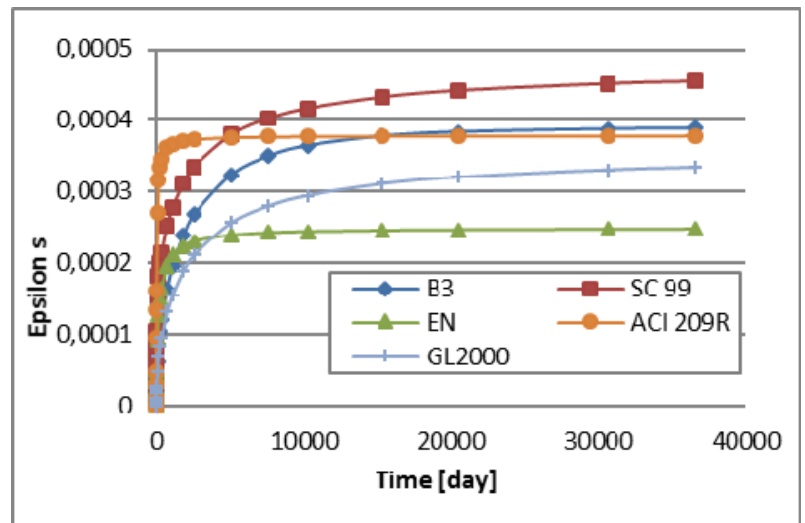

a)

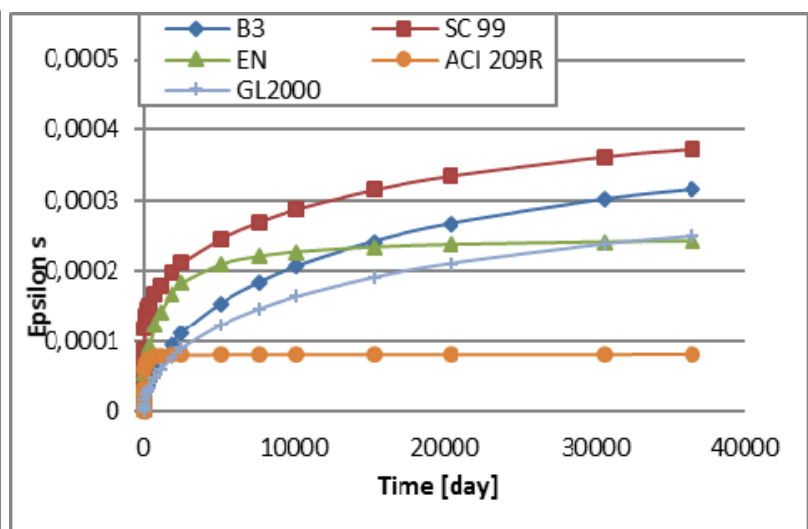

b)

FIGURE VI. COMPARED SHRINKAGE, C50/60 CONCRETE, 0.35 M, NORMALLY HARDENING CEMENT, TREATMENT TIME 2 DAYS, RELATIVE HUMIDITY 70\%), THICKNESS A) 0,35 M, B) $1 \mathrm{M}$

\section{CONCLUSIONS}

As it is evident from the presented graphs, predictive models show significant differences in determining the creep coefficient and the relative shrinkage. If we make an assumption and we choose the B3 model as a benchmark for other models, especially because this model is very complex with the largest number of input parameters and based on a large number of comparative experiments, it can be stated as follows:

- Model GL 2000 approaches the character of B3 model but often with a greater constant intervals.

- Method ACI 209R has a rapid onset and from this point of view differs significantly from the other models in the early stages of creep and shrinkage.

- Method MC2010 has frequently a slightly higher values in comparison with the model B3.

- Methods BS and AS are very simplified and often very distant from the B3 model results.

Due to the assumption of using the model B3 as a benchmark indicator we would not recommend using predictive models listed in ACI 209R, BS and AS. From this perspective suitable models are MC 2010 model and EN 1992-1-1. It is clear that in determining the coefficient of creep and shrinkage is always better to use a combination of several methods for getting an idea of the possible range of predicted values.

\section{ACKNOWLEDGEMENT}

This research was supported by grant no. GAČR 13$15175 \mathrm{~S}$

\section{REFERENCES}

[1] Z. Šmerda, V. Křístek, Creep and Shrinkage of Concrete Elements and Structures, Elsevier, Amsterdam, Oxford, New York, Tokyo, 1988.

[2] EN 1992-1-1: Eurocode 2: Design of concrete structures - Part 1-1: General rules and rules for buildings, 2004.

[3] Z.P. Bažant, S. Baweja, Creep and Shrinkage Prediction Model for Analysis and Design of Concrete Structures: Model B3, ACI Special Publication Creep and Shrinkage of Concrete, 2000.
[4] CEB-FIP Model Code 2010, Volume 1, Bulletin d'Information N. 55, CEB-FIP, 2010.

[5] British Standard, http://www.scribd.com

[6] E. C. Vincent: Compressive creep of a lightweight high strength concrete mixture, Virginia Polytechnic Institute and State University, 2003.

[7] P. Paulík: The effect of curing conditions (in situ vs. laboratory) on compressive strength development of high strength concrete. Procedia Engineering, 65 (2013) 113-119 